\title{
A QUESTÃO DA MORADIA E O PROCESSO DE SEGREGAÇÃO RESIDENCIAL: Notas Críticas
}

\author{
Marcelo Loura de Morais ${ }^{i}$
}

\begin{abstract}
Resumo: este artigo pretende apresentar e debater de forma crítica o problema da falta de moradia, investigar suas origens e causas sob o modo de produção capitalista. Analisamos também a sua principal consequência que é formação de um espaço segregado e dividido em enclaves fortificados e condomínios residenciais de luxo; e grandes aglomerados urbanos com condições precárias de vida.
\end{abstract}

Palavras-chave: Habitação; segregação; fragmentação; moradia.

\section{THE HOUSING ISSUE AND THE PROCESS OF RESIDENTIAL SEGREGATION: CRITICAL NOTES}

\begin{abstract}
: this article aims to present and critically discuss the problem of homelessness, to investigate its origins and causes under the capitalist mode of production. We also analyzed its main consequence, which is the formation of a segregated space divided into fortified enclaves and luxury residential condominiums; and large urban agglomerations with precarious living conditions.

Keywords: habitation; segregation; fragmentation; housing.
\end{abstract}

\section{LA CUESTIÓN DE LA VIVIENDA Y EL PROCESO DE SEGREGACIÓN RESIDENCIAL: NOTAS CRÍTICAS}

Resumen: este artículo pretende presentar y discutir críticamente el
problema de la falta de vivienda, investigar sus orígenes y causas en el
modo de producción capitalista. También analizamos su principal
consecuencia, que es la formación de un espacio segregado dividido
en enclaves fortificados y barrios cerrados; y grandes aglomeraciones
urbanas con precarias condiciones de vida.
Palabras clave: habitación; segregación; fragmentación; las viviendas.

' Marcelo Loura de Morais. Doutorando em Geografia pela UFRJ (Universidade Federal do Rio de Janeiro) e Professor de ensino fundamental II na Prefeitura municipal do Rio de Janeiro. https://orcid.org/00000002-4241-7678. 


\section{Introdução: (de Engels a Mike Davis - ou como as moradias precárias tornaram-se um fenômeno de expressão mundial)}

Em toda a parte do terceiro mundo a escolha da moradia é um cálculo complicado de considerações ambíguas (Mike Davis, 2006: 39).

Na madrugada do dia primeiro de maio de 2018, uma terça feira, um prédio em péssimas condições infraestruturais, localizado na região central de São Paulo, próximo ao Largo Paissandu, se incendiou e desabou. Aproximadamente 400 pessoas eram cadastradas como moradores dessa ocupação (MTST, 2018). Longe de ser uma exceção, esse acontecimento trouxe à tona um grande problema contemporâneo brasileiro: a enorme quantidade de pessoas sem-teto. Segundo algumas estimativas, o número se aproxima de 6,35 milhões de famílias sem casa no Brasil (BOULOS, 2018). Acaba não restando alternativa para grande parte da população pobre a não ser se abrigar em moradias precárias estabelecidas em áreas de risco ambiental ou via ocupação que inclui prédios públicos e privados antigos, abandonados em estado precário do ponto de vista estrutural localizados nos centros das grandes cidades.

São inúmeros os relatos de como a questão da habitação é um problema crônico do modo de produção capitalista e que ainda persiste principalmente nos países periféricos. Mike Davis (2009), em seu livro Planeta Favela, demonstra como a expansão generalizada da pobreza e das péssimas condições de vida urbana no terceiro mundo tem relação direta com a grande expansão da vida urbana e industrial dos países periféricos no século XX. Problema inclusive já detectado por ENGELS (2010) em seu estudo clássico, publicado originalmente em 1845, sobre a situação da classe trabalhadora na Inglaterra, como consequência da grande expansão urbana decorrente da primeira Revolução Industrial. Da mesma forma que encontrávamos em Londres “onde vive a maior parte da classe operária (...) pátios estreitos, lamacentos, mal arejados e com esgotos precários, alinhando-se entre oito e vinte prédios" (ENGELS, 2010: 80), atualmente "existem provavelmente mais de 200 mil favelas, cuja população varia de algumas centenas a mais de 1 milhão de pessoas em cada uma delas (DAVIS, 2009: 37). Dos quais, "sozinhas, as cinco grandes metrópoles do sul da Ásia contêm cerca 
de 15 mil comunidades faveladas cuja população total excede os 20 milhões de habitantes" (ibid). Países como Tanzânia, Etiópia e Bangladesh possuem, por exemplo, os percentuais de população urbana morando em favelas de $92,1 \% ; 99,4 \%$ e $84,7 \%$ respectivamente (DAVIS, 2006: 34).

Somente na região metropolitana de São Paulo, o déficit habitacional chega a um milhão

“... a questão da moradia

é um problema de difícil

resolução sob os limites

do capitalismo, pois

mesmo projetos

reformistas são incapazes

de solucionar esta

situação, e "uma solução

que sempre gera de novo

seu próprio problema",

não é, 'portanto solução

nenhuma' (Engels)". de unidades, segundo cálculos realizados pela FGV (Fundação Getúlio Vargas) em 2018 ${ }^{1}$. A questão da moradia tornou-se tão problemática na maior metrópole brasileira, que está se proliferando uma forma habitacional precária onde as pessoas habitam o interior de buracos presentes em viadutos e pontes. O viaduto Rudge, por exemplo, onde se localiza a Favela do Moinho, possui cerca de 70 famílias morando em casas improvisadas sob a estrutura do viaduto. ${ }^{2}$

Em todo o terceiro mundo, a escolha por uma moradia se torna um caso dramático, sempre "encurralados" pela necessidade de morar próximo ao trabalho, mas ao mesmo tempo, empurrados para a "periferia distante" pelo alto preço da terra urbana que se valoriza com o crescimento das cidades. A única saída encontrada é a moradia em lugares de alto risco e vulnerabilidade (que justamente devido à essa característica, não são interessantes para o mercado) como morros e encostas com grande declividade e por isso sujeitas a desmoronamento, margens dos rios, sujeitos ao risco das enchentes provenientes da "temporada de chuvas no verão", e até mesmo casos emblemáticos como os "homens engaiolados" de Hong Kong que moram em antigos poços de ventilação com espaço vital de 1,8 metros quadrado por

\footnotetext{
1 O estudo mostra que o déficit da região metropolitana chegou a 1,024 milhão de unidades em 2018, o que representa um aumento de 110,8 mil unidades em relação ao ano anterior. Desde 2011, esse déficit dobrou de tamanho, ao crescer a um ritmo médio de $10 \%$ ao ano. - Disponível em: https://valorinveste.globo.com/produtos/imoveis/noticia/2020/02/19/deficit-habitacional-em-saopaulo-bate-recorde-e-supera-1-milhao-de-moradias.ghtml. Acesso em mar. 2021.

2 Veja a reportagem a seguir: https://tab.uol.com.br/edicao/pelas-entranhas/. Acesso em mar. 2021.
} 
pessoa, e a "Cidade dos Mortos", uma favela que se estabeleceu em cemitérios onde repousavam os restos mortais de antigos faraós no Egito (ibid: 43 e 45).

Em todos estes casos, os moradores, além de enfrentar o drama das condições precárias de vida (sanitárias, estruturais, lazer...), precisam lidar com a possibilidade de ser expulsos, pois, não possuem a propriedade da terra em que habitam. Estão em uma suposta condição de "ilegalidade". Contudo, é importante ressaltar que esta condição de ilegalidade "não é resultado de uma atitude de confrontação em relação à legislação, mas sim resultado da falta de opções" (MARICATO, 2018: 3). Essa falta de opções se acentua em um contexto de reestruturação produtiva do capitalismo e reajuste no modo de acumulação decorrentes da crise do fordismo (HARVEY 2007), onde se proliferam "desregulamentações, privatizações, precariedade nas relações de trabalho (...) ampliação da desigualdade e hegemonia do capital financeiro" (MARICATO, 2015: 13). Essa guinada neoliberal impacta profundamente na gestão do território e na produção do espaço urbano, pois investimentos sociais em áreas como transporte, habitação e saneamento escasseiam cada vez mais.

Além disso, mesmo quando o Estado resolve investir de maneira mais enfática em infraestrutura urbana, acaba promovendo um processo de especulação imobiliária ocasionando uma significativa elevação do preço dos imóveis e da terra, também acentuando a expulsão dos pobres das regiões mais valorizadas, colaborando para o déficit habitacional. Nos anos recentes de crescimento econômico e relativa distribuição de renda dos governos petistas, por exemplo, o que aconteceu foi que: "entre janeiro de 2008 e janeiro de 2015 , o preço dos imóveis subiu 265 ,2\% no Rio de Janeiro; e $218,2 \%$ em São Paulo" (MARICATO, 2015 p. 39). Ocorre que a relação oferta-demanda é sempre desproporcional, pois o tempo de produção de uma residência é muito longo, logo ao tentar estimular a demanda se cria a especulação e não a produção, como a crise de subprimes de 2008 tão bem demonstrou (HARVEY, 2014: 98).

Dessa forma nota-se como a questão da moradia é um problema de difícil resolução sob os limites do capitalismo, pois mesmo projetos reformistas são incapazes de solucionar esta situação, e "uma solução que sempre gera de novo seu próprio problema", não é, “portanto solução nenhuma” (ENGELS, 2015: 56) 


\title{
Sobre a questão da moradia
}

Ao explicar como a burguesia resolve a questão da moradia Engels em 1872 afirmou:

\begin{abstract}
Sem a escassez de moradia não há como subsistir uma sociedade na qual a grande massa trabalhadora depende exclusivamente do salário e, portanto da soma de mantimentos necessária para garantir a sua existência e reprodução; (...) quando novos melhoramentos mecânicos tiram incessantemente trabalho a grandes massas de operários; quando crises industriais violentas e cíclicas determinam, por um lado, a existência de um importante contingente de reserva de desempregados e, por outro, lançam momentaneamente para a rua a grande massa dos trabalhadores; quando estes são amontoados nas grandes cidades e isto a um ritmo mais rápido que o da construção de habitações nas circunstâncias atuais e quando aparecem sempre inquilinos até para os chiqueiros mais infames; (...) Numa tal sociedade, a crise da habitação não é um acaso, é uma instituição necessária; ela só pode ser eliminada, tal como as suas repercussões para a saúde, etc, se toda a ordem social de que ela decorre for completamente transformada (ENGELS, 2015: 71).
\end{abstract}

Nas sociedades escravocratas (pré-capitalistas), a responsabilidade de prover a moradia e a subsistência dos trabalhadores era dos senhores de escravos, contudo a emergência do trabalho livre cria a necessidade do trabalhador pagar pela própria habitação a partir de seus salários. Ou seja, "a questão da moradia é primordialmente a de sua crise" (CASTELLS, 1983: 183).

A habitação deve ser considerada um bem insubstituível e necessário, pois garante segurança, privacidade e é essencial para a reprodução e existência da força de trabalho. É também um bem fixo no espaço geográfico, e seu valor se relaciona diretamente com o solo urbano e o "valor da terra". Dessa forma, na sociedade capitalista deve ser considerada uma "mercadoria especial", que possui algumas especificidades que historicamente impediram a realização desta posse por parte de grande parte da população. 
Essas especificidades que impediram historicamente que grande parte da classe trabalhadora obtivesse suas moradias e que até mesmo atingiu outras camadas sociais pequeno-burguesas em algumas ocasiões, são as seguintes:

1) Por ser um dos elementos essenciais da reprodução da força de trabalho, ela segue os movimentos de concentração e dispersão populacional causados pela revolução industrial, "com efeito, no local onde a indústria coloniza o espaço, necessita organizar ainda que a nível de acampamento, a residência da mão-de-obra necessária" (CASTELLS, 1983: 187), suscitando um grande movimento migratório cuja dimensão ultrapassa amplamente as capacidades de construção de uma cidade herdada de um modo de produção anterior. Podemos definir, portanto, que "quanto maior a taxa de crescimento industrial capitalista, mais intenso é o crescimento urbano, maior é a tendência à concentração em grandes aglomerações e maior é a penúria das moradias" (ibid: 188).

2) Existe uma profunda relação entre a mercadoria "moradia" e o solo urbano, e como existem várias influências que determinam o valor da terra (amenidades, vias de transportes, distância em relação ao centro, etc) o custo de arcar com uma boa moradia é diretamente proporcional à localização desta mesma residência. É sempre bom lembrar que:

Os capitais que ganham com a produção e exploração do espaço urbano agem em função do seu valor de troca. Para eles a cidade é mercadoria (...) a terra urbana, constitui sempre uma condição de monopólio - ou seja, não há um trecho ou terreno igual a outro, e sua localização não é reproduzível - estamos diante de uma mercadoria especial que tem o atributo de captar ganhos sob a forma de renda. A cidade é um grande negócio e a renda imobiliária, seu motor central (MARICATO, 2015: 23).

É inimaginável conceber que os agentes hegemônicos modeladores do espaço urbano (CORRÊA, 1989) irão reservar as melhores localidades da terra urbana para habitações populares, enquanto podem aproveitar da renda fundiária tanto para especular (manter os vazios urbanos para esperar futuras valorizações), ou para a construção de empreendimentos comerciais mais lucrativos. Este inclusive é um efeito multiplicador da crise habitacional, pois "em situação de penúria, desenvolve-se a especulação, os 
preços sobem, a rigidez social faz-se maior. A dificuldade do problema amortece as iniciativas para resolvê-lo, contribuindo assim para agravá-lo e para desenvolver em espiral o círculo vicioso da crise" (CASTELLS, 1983: 188).

3) A demanda efetiva é a única levada em conta pela iniciativa privada, dessa forma na ausência de intervenção pública - seja através de financiamentos (incentivando a demanda), ou em subsídios fiscais a construtoras (incentivando a oferta), o mercado restringe a construção de casas a um estrato muito limitado da população. No caso de São Paulo, por exemplo, os ganhos necessários para se contrair um financiamento exigem mais de 10 salários mínimos, esse limite exclui $60 \%$ da população da região metropolitana, que ou opta pela informalidade, ou aguarda políticas públicas (MARICATO, 2018: 4)

4) E por fim, mesmo nos momentos de crescimento econômico e expansão urbana, quando investimentos privados e públicos se combinam para a construção de habitações, o resultado não ocasiona necessariamente o aumento significativo de casas disponíveis, pois "o tempo de produção e circulação para casas e imóveis comerciais é muito longo em comparação com a maior parte das outras mercadorias" (HARVEY, 2014: 98). A quantidade existente de propriedades vendidas é, na verdade, muito grande em relação à capacidade de produzir, ou seja, a oferta total de moradias é "relativamente inelástica". Mesmo nos países desenvolvidos, no período de crescimento econômico do pós-guerra a quantidade de habitações não aumentou mais do que $3 \%$ ao ano (ibid: 99). Dessa forma uma grande quantidade de capital disponível, em busca de valorização imediata, ao se abrigar no setor imobiliário em vez de financiar a construção de habitações populares, movimenta uma intensa "bolha financeira". Este foi um dos efeitos causadores da devastadora crise imobiliária dos Estados Unidos:

Enormes quantidades de capital fictício afluíram para o financiamento imobiliário, mas só uma pequena parte foi usada para a construção de novas moradias. O mercado de hipotecas subprime, que ficava em torno de 30 bilhões de dólares em meados da década de 1990, aumentou para 130 bilhões por volta do ano 2000, e atingiu um pico inédito de 625 bilhões de dólares em 2005 (HARVEY, 2014: 100). 
O problema do déficit habitacional, portanto, está longe de ser um problema conjuntural, ou resultado de algum "desarranjo econômico", mas decorre diretamente das condições de funcionamento do modo de produção capitalista. Ao afetar camadas médias da sociedade, a crise habitacional até pode emergir nos debates de alguns reformistas bem intencionados, contudo as soluções não chegam a "arranhar" a superfície da questão. Nos países periféricos como o Brasil, por exemplo, onde o welfare state é somente uma caricatura e a desigualdade social atinge índices alarmantes, a maioria da população pobre soluciona a questão da moradia através da ilegalidade (moradia em aglomerados subnormais) ${ }^{3}$, da autoconstrução e dos loteamentos populares irregulares na periferia (MARICATO, 2018). Esta lógica colabora significativamente para a redução do custo de reprodução da força de trabalho, ampliando a acumulação capitalista nos países subdesenvolvidos (OLIVEIRA, 2013: 59).

\section{O processo de segregação residencial e seus impactos na estrutura urbana}

A segregação é parte do problema maior relacionado à questão da habitação, afinal "a distribuição das residências no espaço produz sua diferenciação social e especifica a paisagem urbana" (CASTELLS, 1983: 210). A cidade deve ser entendida sempre como um espaço fragmentado e articulado, sendo a segregação um dos mais importantes processos espaciais que criam a fragmentação do espaço urbano (CORRÊA, 2013: 39). Ela é, portanto, a forma final de um complexo processo que molda as cidades na história da urbanização. CASTELLS (1983) define a segregação urbana como a "tendência à organização do espaço em zonas de forte homogeneidade social interna e com intensa disparidade social entre elas, sendo esta disparidade compreendida não só em termos de diferença, como também de hierarquia" (ibid: 210). A segregação é resultado direto de "um efeito da distribuição do produto entre os sujeitos, e do produto-moradia no

\footnotetext{
3 Aglomerados subnormais: para o IBGE (2006): É o conjunto constituído por 51 ou mais unidades habitacionais caracterizadas por ausência de título de propriedade e pelo menos uma das características: - irregularidade das vias de circulação e do tamanho e forma dos lotes e/ou - carência de serviços públicos essenciais (como coleta de lixo, rede de esgoto, rede de água, energia elétrica e iluminação pública).
} 
espaço, bem como da correspondência entre estes dois sistemas de distribuição" (ibid: 213).

A temática da segregação residencial foi abordada inicialmente sob a perspectiva da "competição, dominação e sucessão" da Ecologia Humana, seu principal expoente Robert Park, determinava que "las condiciones que afectan y controlan los movimientos y el tamaño de la población en las sociedades humanas son más complejas que en las comunidades vegetales y animales, pero muestran similitudes extraordinárias" (PARK, 199: 131). A partir da perspectiva de "áreas naturais" encarava que os fatores que moldavam o "mosaico social" da cidade capitalista eram essencialmente étnicos, comandado por fatores semelhantes aos biológicos. Isto criava a tendência aos indivíduos de se aglomerar em grupos semelhantes: "unidades individuales mantienen relaciones de interdependencia mutua cuya naturaleza es simbiótica antes que social" (ibid: 129).

Posteriormente, outros autores de matrizes teóricas distintas irão abordar a questão da segregação sob outra perspectiva, rejeitando a tese das "áreas naturais" e determinações biológicas. Harvey (1985), em seu texto "Class Structure and the Theory of Residential Diffrentiation", irá identificar três tipos de forças que comandam o processo de diferenciação social da população urbana, de origem exclusivamente socioeconômica:

1) A primary force arising of the power relation between capital and labor;

2) A variety of secondary forces arising out of the contradictory and evolutionary character of capitalism which encourage social differentiation along lines defined by the division of labor and specialization (...)

3) Residual forces reflecting the social relations established in a preceding or geographically separate but subordinate mode of production (HARVEY, 1985: 111).

Essas forças primárias atuam dividindo a sociedade em duas classes sociais: proprietários dos meios de produção / proletariado. Posteriormente as forças secundárias atuam diversificando a divisão social do trabalho criando estratos médios 
das camadas sociais. "Essas complexificam a sociedade capitalista, fragmentando-a em inúmeras classes e frações de classe" (CORRÊA, 2013: 41). As forças residuais por fim, se referem à classes que permanecem de modos de produção anteriores como antigos proprietários de terra que vivem da renda fundiária e migrantes oriundos do campo que ainda não se estabeleceram enquanto força de trabalho no meio urbano. É a partir da lógica contraditória e antagônica oriunda dessas forças que a cidade capitalista se configura enquanto um espaço fragmentando e segregado, abrigando essas distintas classes sociais e suas frações. Para CORRÊA (2013: 42) inclusive: "admite-se assim, que quanto mais intensa a fragmentação social, mais complexa será a segregação residencial".

O conceito de segregação para SPOSITO (2013) deve ser compreendido em sua complexidade e multidimensionalidade, muito além do que a mera separação física de grupos diferentes, ele significa também "a desigualdade dos direitos de acesso à cidade, no sentido de dela se apropriar e de participar completamente." (SPOSITO, 2013: 85). Por isso mesmo é que ela deve ser vista como uma "mescla de condicionantes e expressões objetivas e subjetivas" (ibid: 66). Isto significa necessariamente que ainda que as barreiras físicas (como os muros, rios, estradas, etc), ou até mesmo a distância atuem para separar uma parte da cidade das outras, a dimensão subjetiva também deve ser levada em conta, afinal "os indivíduos elaboram valores, expectativas e hábitos e se preparam para como adultos, ingressar no mercado de trabalho, desenvolvendo ainda um dado estado de consciência nesse contexto de homogeneidade social" (CORRÊA, 2013: 43). Ou seja, existe uma distância física, mas também social.

A partir desta conceituação, podemos definir a partir de (CORRÊA, 1989; CORRÊA, 2013) dois tipos de processos que comandam as lógicas de segregação:

a) autossegregação: quando grupos de alto status sociais criam áreas nobres, tornandoas exclusivas aos seus membros devido ao alto preço da terra urbana. "Graças aos cada vez mais eficazes meios de controle do espaço, as áreas autossegregadas fornecem segurança aos seus habitantes, ampliando o status e prestígio que possuem" (CORRÊA, 2013: 43). É importante ressaltar que esta prática é possibilitada devido ao controle em 
algum nível do aparelho do Estado que as elites possuem. Além do acesso às informações sobre a cidade e seu funcionamento.

b) segregação imposta e induzida: é um processo imposto às classes sociais menos favorecidas, são os famosos processos de "limpeza" social através da expulsão de pobres de áreas valorizadas da cidade. A diferença entre as duas é pouco espessa, contudo, assume-se que na induzida aqueles envolvidos ainda possuem algumas escolhas de localidade possíveis.

Historicamente a segregação resultou em espacialidades que formavam um relativo padrão, essas tendências foram identificadas e transformadas em modelos por várias correntes de pensamento cientifico que estudavam as grandes cidades em transformação. A cidade pré-industrial remetia ao modelo centro-periferia, onde a elite ocupa o centro e os locais de menor prestígio eram mais afastados. O prestígio social era proporcionalmente aumentando enquanto se diminuía a distância ao centro, esse modelo é o denominado por CORRÊA (2013: 46) de Kohl-Sjoberg. Posteriormente quando a industrialização se disseminou pela Europa, e as grandes cidades capitalistas passaram por um enorme crescimento populacional, se identificou que o padrão de segregação possuía uma espacialidade inversa: nas primeiras zonas próximas ao centro residiam os imigrantes mais pobres que moravam em cortiços, enquanto que as populações de status sociais mais elevados foram morar nos subúrbios afastados da degradação do centro. Este é o modelo de Burguess (CORRÊA, 2013: 47). Por fim o modelo de Hoyt identificava que a expansão espacial das cidades se fazia por setores, e não através dos círculos concêntricos. "A expansão desses setores se fazia, por certo período de tempo, ao longo da mesma direção" (ibid: 48) Uma estrutura social mais complexa era formada, onde a expansão da população de alto status sociais acompanhava os setores de amenidades.

Os padrões de segregação socioespacial das metrópoles contemporâneas são cada vez mais complexos e diversificados: o medo da violência, do encontro com o outro e a fuga dos espaços públicos fomenta uma cidade de "enclaves fortificados" (CALDEIRA, 2000: 258), com lugares cada vez mais vigiados e controlados (DAVIS, 1993) onde a vida 
contemporânea se torna cada vez mais "fragmentada, dividida e propensa a conflitos" (HARVEY, 2014: 43).

\section{A crise urbana toma forma: a cidade fragmentada e dividida}

Bem vindo à Los Angeles pós-liberal, onde a defesa dos estilos de vida de luxúria se traduz pela proliferação de novas formas de repressão nos espaço e no movimento, o todo apoiado na "resposta armada" ubíqua. Esta obsessão por sistemas de segurança física e, colateralmente, pelo controle arquitetônico das fronteiras sociais, tornou-se o zeitgeist da reconstrução urbana, a narrativa mestra do meio construído emergente nos anos noventa (DAVIS, 1993: 205).

A presença dos condomínios fechados na paisagem urbana foi denominada por CALDEIRA (2000: 258) de "enclaves fortificados", e são "fisicamente demarcados e isolados por muros, grades, espaços vazios e detalhes arquitetônicos. São voltados para o interior e não em direção à rua, cuja vida pública rejeitam explicitamente" (ibid). Além de serem constantemente "controlados por guardas armados e sistemas de segurança, que impõem as regras de inclusão e exclusão" (ibid). Estes empreendimentos estão mudando a forma como as pessoas de classe média e alta vivem a cidade. O padrão de segregação espacial se transforma, já que a distância não é mais suficiente para demarcar o território de pobres e ricos, torna-se necessário criar essa divisão a partir de limites claros de fronteiras como o muro e a segurança armada.

Dessa forma, de maneira cada vez mais explícita, os gestores urbanos buscam políticas para criminalizar e expulsar os moradores de rua do espaço urbano. Nos Estados Unidos, por exemplo, um estudo do Centro Nacional para Moradores de Rua e Pobreza (NLCHP) indicou que em 187 cidades houve tentativas de criminalizar a moradia de rua (O GLOBO, 2014: s/p). Neste conflito pelo espaço público, as elites demonstram o quanto a presença da pobreza nas ruas se torna um "constrangimento para a cidade":

Aronal Abbot, um ex-delegado da Pensilvânia, de 90 anos e atual diretor da "Ame seu vizinho", uma organização que tem alimentando moradores de rua por mais de 20 anos, diz que "os moradores de rua são um constrangimento para a cidade", e que já 
tentaram, sem sucesso, por cinco vezes, na justiça, impedir que ele servisse a comida aos pobres, todas as quartas-feiras, na orla turística da praia.

A cidade, ele conta, quer muito que os moradores de rua vão embora: - Eles gostariam de colocá-los em um ônibus e mandá-los para Miami ou para Palm Beach. É praticamente uma limpeza étnica. Mas eles não vão conseguir - completa.

- Eles querem nos tirar da cidade de todas as maneiras possíveis diz Jimmy Singleto, de 59 anos, que já foi um cabelereiro em Nova York, mas agora vive nas ruas. - Eles gostariam que nós morrêssemos. (O GLOBO, 2014: s/p)

No Brasil também despontam exemplos dessa modalidade hostil de arquitetura urbana contra os indesejados, recentemente em São Paulo, o Padre Julio Lancelloti, que possui um histórico de militância pelos direitos humanos, foi filmado quebrando a marretadas pedras, colocadas pela prefeitura de São Paulo embaixo de um viaduto da Zona Leste, que possuíam o intuito justamente de afastar moradores de rua daquele local ${ }^{4}$.

Para DAVIS (1993: 207), a "consequência universal e inelutável desta cruzada pela segurança da cidade é a destruição do espaço público acessível". Estes enclaves fortificados consolidam um "relacionamento de negação e ruptura com a cidade" (CALDEIRA, 2000: 259). O estilo moderno de espaço público que permitia, ainda que de maneira limitada, o encontro dos desiguais vai se deteriorando, e ambientes que comportem uma maior heterogeneidade social passam a ser vistos como "espaços perigosos." Os comerciais de moradia para as classes médias e altas enfatizam constantemente a oportunidade de se fugir da confusão, da mistura, da poluição e do barulho que os ambientes urbanos passam significar, pois "supõe-se que os condomínios fechados sejam mundos separados. Seus anúncios propõem um 'estilo de vida total' superior ao da cidade" (ibid).

A redefinição dos espaços públicos e privados contribui para a fragmentação da cidade contemporânea e cria uma policentralidade a partir do surgimento das "edge cities" e

\footnotetext{
4 https:/g1.globo.com/sp/sao-paulo/noticia/2021/02/02/padre-julio-lancelotti-quebra-a-marretadaspedras-instaladas-sob-viadutos-pela-prefeitura-de-sp.ghtml. Acesso em mar. 2021.
} 
da proliferação dos novos centros de consumo vigiados e privatizados: os shoppings centers. A busca pela "auto segregação" a partir do isolamento e distância da vida urbana incentiva a criação de empreendimentos imobiliários nos limites da cidade, criando uma nova frente de expansão urbana contínua. O exemplo, mais bem acabado deste processo no Brasil encontra-se nos municípios de Barueri e Santana de Parnaíba, localizados na Região Metropolitana de São Paulo, às margens da Rodovia Castelo Branco: o Alphaville (SOUZA, 2006: 478).

Este complexo residencial é uma expressão significativa do auto-enclausuramento: localizado bem distante do CBD (Central Businesses District ${ }^{5}$ ), isolado, bem vigiado, "em geral quem não mora em Alphaville lá vai só a trabalho" (ibid), possui dúzias de consultórios médicos, casas de câmbio, lojas, comércio, faculdades, shoppings e até galerias de arte. Esta solução escapista contribui para a formação de "arquipélagos ou ilhas de prosperidade", fragmentando ainda mais o "tecido sociopolitco espacial das metrópoles". Resumidamente:

A multiplicação de "condomínios exclusivos", associada à "decadência", ao monitoramento e à "privatização" de espaços públicos, na esteira da transformação destes em espaços de hipervulnerabilidade, constitui uma tendência em muitas cidades que, a prosseguir irá fraturando, fragmentado a urbe- interditando acessos, formando "ilhas" e "arquipélagos" de segurança (SOUZA: 488).

A estrutura urbana se orienta para um padrão fragmentado e dividido, em que o encontro entre os desiguais é desestimulado e as moradias se voltam para o interior de condomínios murados, negando a vida urbana. Ainda que diferentes metrópoles apresentem suas particularidades, podemos observar essas tendências gerais tanto nas grandes cidades dos países centrais como nas metrópoles periféricas como São Paulo e Rio de Janeiro.

\footnotetext{
${ }^{5}$ (Área Central de Negócios) - Consiste na área urbana que funciona como principal centro financeiro da cidade.
} 


\section{Considerações finais}

O grande déficit habitacional contemporâneo é expressão de profundas contradições do desenvolvimento urbano capitalista. As formas desse processo são mais visíveis nos países periféricos, onde na maioria das vezes a "cidade ilegal" supera quantitativamente a "cidade oficial". Em alguns casos, mesmo os trabalhadores formais acabam se utilizando da autoconstrução e da ocupação de áreas ambientalmente degradáveis para resolver a questão da moradia devido ao aumento crescente do preço do solo urbano e a incapacidade de conseguir receber algum financiamento. No Brasil, em cidades como Rio de Janeiro e São Paulo que sofreram intensamente nos últimos anos com a especulação imobiliária resultante do ciclo de grandes eventos esportivos (Copa do Mundo - 2014 e Olimpíadas - 2016) isso se tornou muito evidente, intensificando os conflitos pelos usos do solo urbano, entre os atores hegemônicos - incorporadores imobiliários e capital financeiro, e grupos socialmente excluídos - ocupações de grupos sem-teto e militantes (SOUZA, 2013).

A expressão espacial mais visível desta lógica mercadológica do uso do espaço urbano é a cidade profundamente segregada. A heterogeneidade social constantemente se torna uma ameaça para as classes médias e altas e o medo do "outro" fomenta reações individualistas e escapistas. A projeção espacial deste comportamento é a "cidade de muros" (CALDEIRA, 2000) em que cada vez mais a alteridade é impossível de ser praticada já que o encontro com o "outro" é dificultado de todas as formas.

\section{Referências Bibliográficas}

BOULOS, Guilherme. Verdades e mentiras sobre os sem-teto. Disponível em: $<$ http://www.psol50.org.br/guilherme-boulos-verdades-e-mentiras-sobre-ossem-teto /> [2018] Acesso em 27 mai. 2018.

CALDEIRA, Teresa, Pires do Rio. Cidade de muros: crime, segregação e cidadania em São Paulo. São Paulo: Edusp, 2000.

CASTELLS, Manuel. O debate sobre a teoria do espaço (cap. 3) In: A questão urbana. Rio de Janeiro: Paz e Terra, 1983, p.145 a 294. 
CORREA Roberto Lobato. O Espaço Urbano. 1ạ Ed. Rio de Janeiro: Editora Ática, 1989.

Segregação residencial: classes sociais e espaço urbano. In: VASCONCELOS, Pedro de A.; CORRÊA, Roberto L.; PINTAUDI, Silvana Maria. A cidade contemporânea: segregação espacial. São Paulo: Contexto, 2013.

DAVIS, Mike. Fortaleza LA (cap. 4). In: Cidade de Quartzo: Escavando o futuro em Los Angeles. São Paulo: Editora Página Aberta, 1993, p.205 a 233. . Planeta Favela. São Paulo: Boitempo, 2006.

ENGELS, Friedrich. A situação da classe trabalhadora na Inglaterra. São Paulo: Boitempo, 2010. . Sobre a questão da moradia. São Paulo: Boitempo, 2015.

HARVEY, David. Class structure and the Theory of residential differentiation (cap. 4). In: The urban experience. Baltimore: The Johns Hopkins University Press, 1985, p.109 - 124.

. Condição Pós-moderna. 13a Ed. São Paulo: Edições Loyola, 2007.

- Cidades Rebeldes: do direito à cidade à revolução urbana. São Paulo: Martins Fontes, 2014.

IBGE. Aglomerados subnormais: informações territoriais. Disponível em <https://ww2.ibge.gov.br/home/presidencia/noticias/imprensa/ppts/000000151 64811202013480105748802.pdf> [2010]. Acesso em 28 mai. 2018.

MARICATO, Ermínia. Conhecer para resolver a cidade ilegal. Disponível em: http://www.usp.br/fau/depprojeto/labhab/biblioteca/textos/maricato_conhece rcidadeileg al.pdf >. Acesso em 29 mai. 2018.

Para entender a crise urbana. 1a Ed. São Paulo: Expressão popular, 2015.

MTST - Tragédia no Centro de São Paulo: falta de moradia digna faz mais vítimas. Disponível em: <http://www.mtst.org/noticias/tragedia-no-centro-de-sao-paulofalta-de-moradia-digna-faz-mais-vitimas/> [2018]. Acesso em 27 mai. 2018.

O GLOBO - Nos EUA, cidades aumentam leis que criminalizam moradores de rua. Disponível em: < http://oglobo.globo.com/mundo/nos-eua-cidades-aumentamleis-que-criminalizam-moradores-de-rua-13492846\#ixzz3yrD733gB.> [2014]. Acesso em 28 mai. 2018. 
OLIVEIRA, Francisco de. Crítica à razão dualista: o ornitorrinco. 1a ed. São Paulo: Boitempo, 2013.

PARK, Robert Ezra. Ecología humana (cap. 9) In: La ciudad y otros ensayos de ecología urbana. Barcelona: Ediciones del Serba, 1999. p. 127-140.

SOUZA, Marcelo Lopes de. O desafio da fragmentação o tecido sociopolítico-espacial da cidade (cap. 11). In: A prisão e a ágora: reflexões em torno da democratização e do planejamento e da gestão das cidades. Rio de Janeiro: Bertrand Brasil, 2006, p. 466 a 511.

Semântica urbana e segregação: disputa simbólica e embates políticos na cidade "empresarialista" In: VASCONCELOS, Pedro de A.; CORRÊA, Roberto L.; PINTAUDI, Silvana Maria; A cidade contemporânea: segregação espacial. São Paulo: Contexto, 2013.

SPOSITO, Maria Encarnação B. Segregação socioespacial e centralidade urbana. In: VASCONCELOS, Pedro de A.; CORRÊA, Roberto L.; PINTAUDI, Silvana Maria; $A$ cidade contemporânea: segregação espacial. São Paulo: Contexto, 2013.

Data de Submissão: $18 / 11 / 2020$ Data do Aceite: 17/03/2021 